\title{
ENDODONTIC MANAGEMENT OF THREE ROOTED MANDIBULAR FIRST MOLAR: REPORT OF THREE CASES
}

\author{
Acharya $\mathrm{N}^{1}$, Samant PS ${ }^{2}$, Gautam $\mathrm{V}^{3}$, Singh $\mathrm{O}^{4}$, Srestha $\mathrm{A}^{5}$
}

\begin{abstract}
In everyday endodontic practice, clinicians face various atypical configurations, such as presence of extra root and/or atypical canal configuration. One of the major reasons of the treatment failure is the missed extra root and/or canals. Mandibular first molars typically have two roots (one mesial and one distal), but sometimes present with a supernumerary root either distolingually (radix entomolaris), or mesiobuccally (radix paramolaris). Hence, the thorough knowledge of root canal anatomy and morphology along with its variation is crucial for the successful outcome of the root canal treatment.
\end{abstract}

The aim of this paper is to present and describe the three clinical case reports of three rooted mandibular first molars and its endodontic management.

KEY WORDS: Endodontics, Mandibular first molar, Radix entomolaris, Radix paramolaris

1. Post Graduate Resident, Department of Conservative Dentistry \& Endodontics, UCMS College of Dental Surgery, Bhairahawa, Nepal

2. Professor, Department of Conservative Dentistry \& Endodontics, Saraswati Dental College, Lucknow, India

3. Associate Professor, Department of Conservative Dentistry \& Endodontics, UCMS College of Dental Surgery, Bhairahawa, Nepal

4. Assistant Professor, Department of Conservative Dentistry \& Endodontics, UCMS College of Dental Surgery, Bhairahawa, Nepal

5. Dental Officer, Department of Conservative Dentistry \& Endodontics, UCMS College of Dental Surgery, Bhairahawa, Nepal

\author{
For Correspondence \\ Dr. Nisha Acharya \\ Post Graduate Resident, \\ Department of Conservative Dentistry \& Endodontics, \\ UCMS College of Dental Surgery, Bhairahawa, Nepal \\ Email: me_nisha5@hotmail.com
}




\section{INTRODUCTION}

The endodontic treatment of mandibular molars creates a constant challenge to the clinician because of the highly variable numbers of the roots and root canals. Despite this, the root canal system of mandibular molars presents with fins, accessory, secondary and lateral canals as well as transverse anastomosis. ${ }^{1,2}$ Usually mandibular first molars present with one mesial and one distal root. However, the number and the location of roots and root canals vary greatly. Carabelli was the first to mention an additional third root in distolingual location of mandibular molar in 1844 and Bolk in 1915 described the presence of additional mesiobuccal root. ${ }^{3,4}$ Theses supernumerary roots are called Radix Entomolaris (RE) if located distolingually and radix Paramolaris (RP) if located mesiobuccally. ${ }^{5}$ The identification and external morphology of these supernumerary lingual and buccal roots are described by Carlsen and Alexandersen. ${ }^{6,7}$

Although both RE and RP are a morphological variant and occurrence is rare, the knowledge of its occurrence is important for accurate diagnosis and appropriate treatment. This clinical case reports a mandibular first molar with additional mesiobuccal root (radix paramolaris) and two mandibular first molars with additional distolingual root(radix entomolaris).

\section{CASE REPORTS}

\section{CASE 1}

A 42-year-old female patient with a noncontributory medical history was referred to the Department of Conservative Dentistry and Endodontics from a general dentist with the chief complaint of a localized, dull, momentary pain on chewing in mandibular right first molar, in which the root canal therapy has been previously initiated. On clinical examination right mandibular first molar revealed a temporary restoration but no swelling, sinus tract or associated mobility was seen. The tooth was however tender to percussion. The pre treatment periapical radiograph showed an access cavity has already been made and pulp has been extirpated. Extra root in the form of the morphological variation in the mesial root (radix paramolaris) was evident in the radiograph(Figure 1).

Clinical and radiographic findings lead to a diagnosis of previously initiated therapy and completion of the root canal treatment was planned.
The tooth was isolated under rubber dam. The temporary restoration was removed and access cavity was modified. Two distal and two mesial canal orifices were located.The working length of the canals were determined using apex locator and digital radiograph (Figure 2). Cleaning and shaping was performed using ProTaper (Dentsply Maillefer) hand files till F2 in all four canals. 2.5\% sodiumhypochlorite and $17 \%$ EDTA solution was used as an irrigating solution. After drying the canals with sterile paper points, obturation was performed with Protaper F2 single cone gutta percha and eugenol based sealer. Post obturation radiograph was taken to assess the quality of the obturation (Figure 3). The temporary restoration was then placed and patient was recalled for follow up and placement of permanent restoration.

Figure 1: Pre-operative radiograph showing extra mesial $\operatorname{root}(\mathrm{RP})$



Figure 2: Periapical radiograph for determination of working length reveals three roots

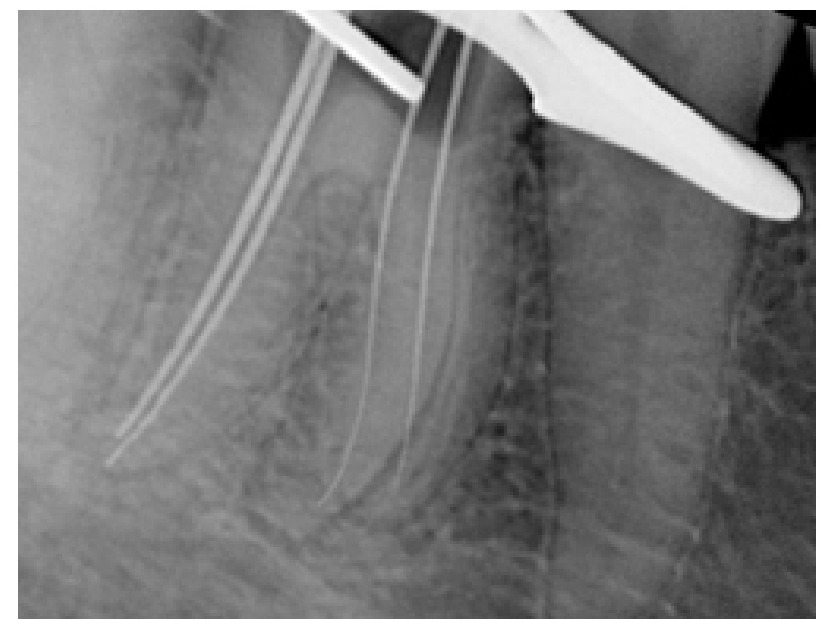


Figure 3: Post obturation radiograph

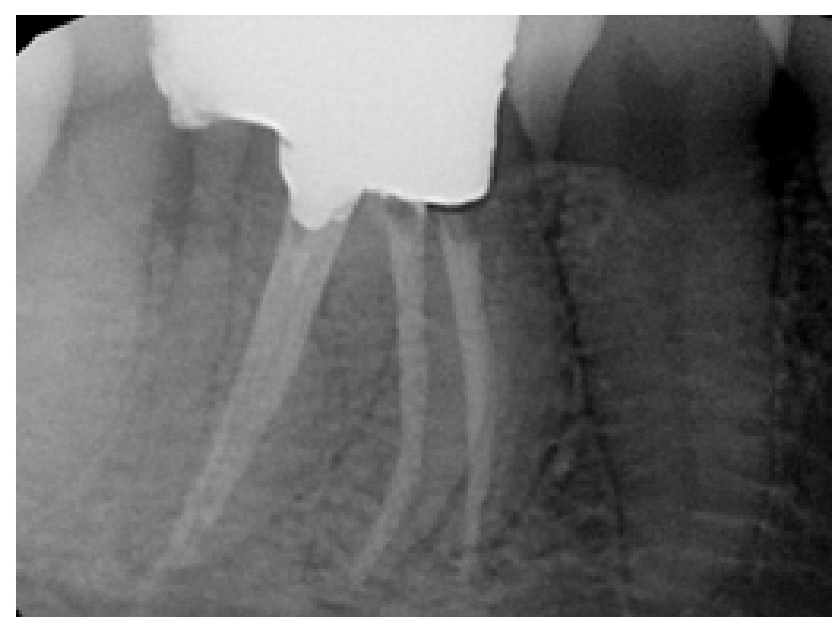

\section{CASE 2}

A 32 year old female patient with non contributory medical history reported to the Department of Conservative Dentistry and Endodontics with the chief complaint of pain in the lower right back tooth since last 6-7 days. The pain was continuous and severe in nature and became worse at night. It got aggravated on taking cold food but relieved by talking analgesics. On examination, a disto occlusal caries was seen on right mandibular first molar. The tooth was slightly tender to percussion but mobility test was negative. The cold test was performed in order to reproduce patient's symptoms. There was a lingering pain sensation even after removal of the stimulus. Routine pre-operative radiograph also revealed a disto occlusal caries approximating the distal pulp horn. A faint outline of an additional distolingual root (RP) was seen in the radiograph (Figure 4).On the basis of clinical and radiographic findings the diagnosis of symptomatic irreversible pulpitis was made and endodontic therapy was planned.

The tooth was isolated under rubber dam after anaesthetizing with $2 \%$ Lignocaine with 1:80,000 adrenaline. The access cavity was made using an endodontic access bur (Dentsply Maillefer). The pulp chamber was cleaned using $2.5 \%$ sodium hypochlorite solution and inspected for canal orifices using endodontic explorer (DG16).Two mesial and two distal canals were located. The glide path was maintained using \#10 $\mathrm{K}$ files. Working length was determined using apex locator and periapical radiographs(Figure 5). The working length radiograph confirms the presence of extra root distally (RE). Bio mechanical preparation of the canals was completed using conventional hand $\mathrm{K}$ files (Dentsply Maillefer) with step back technique. Number $30 \mathrm{~K}$ file was chosen as a master apical file for all four canals. Canals were irrigated with $2.5 \%$ sodium hypochlorite and 17\% EDTA solution. Canals were dried with paper points and master cone radiograph was taken in order to re-confirm the working length.Obturation was performed with lateral condensation technique using gutta percha and eugenol based sealer. The access cavity was cleaned and temporary restoration was placed. Post obturation radiograph was taken to evaluate the quality of the treatment (Figure 6) Patient was recalled for follow up and placement of permanent restoration.

\section{Figure 4: Pre-operative radiograph showing additional} distal root (RE)

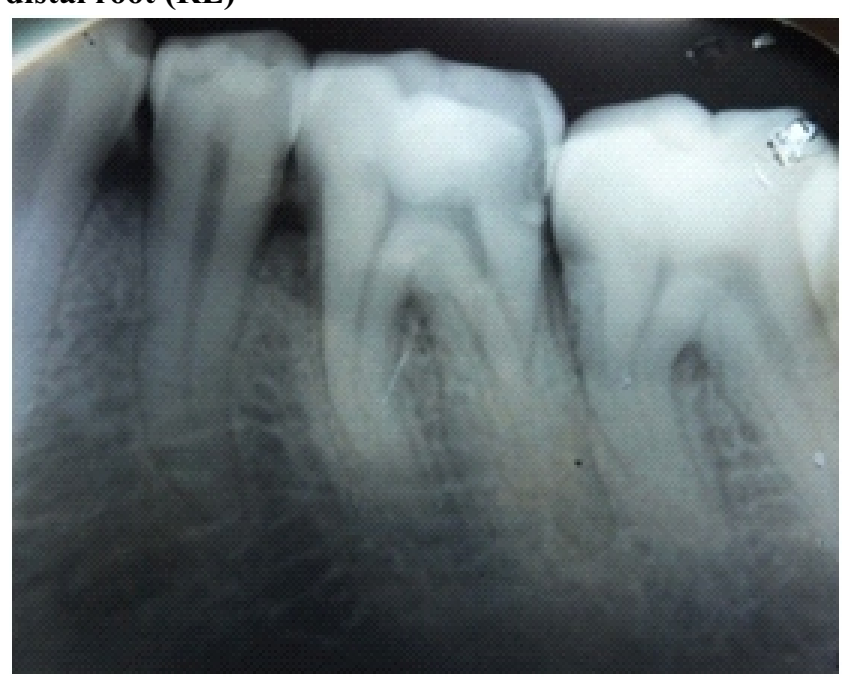

Figure 5: Working length radiograph also reveals additional distal root (RE)

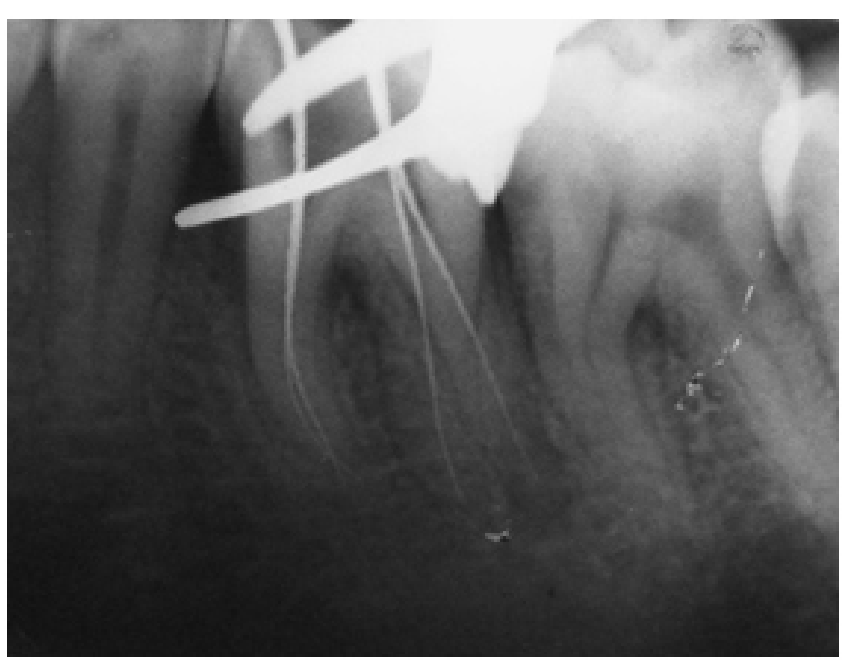




\section{Figure 6: Post obturation radiograph}

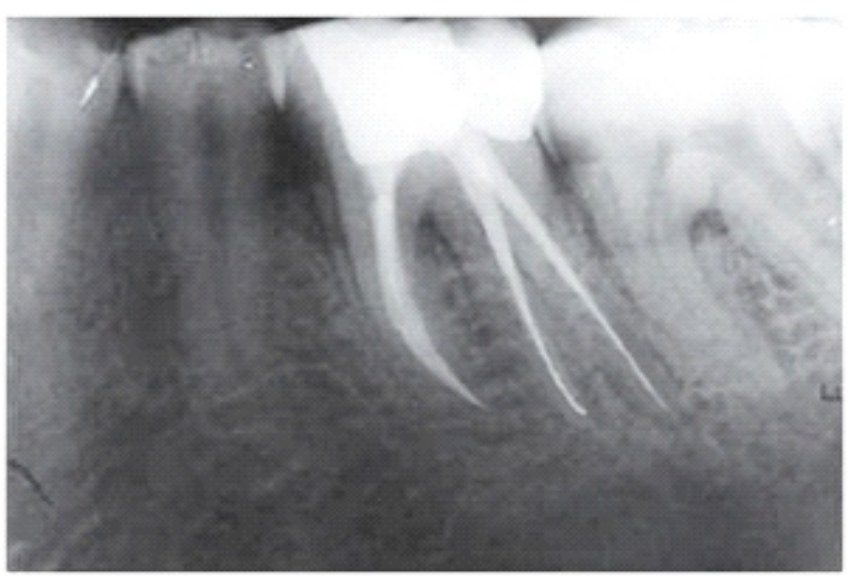

\section{CASE 3}

A 23 year old male patient reported to the Department of Conservative Dentistry and Endodontics with the complaint of a localized steadily provoked momentary pain on chewing in right lower back region since last 1 month. On examination, mandibular right first molar was restored and was tender on percussion but palpation and mobility seems to be normal. There was no history of thermal sensitivity. The vitality tests (thermal and electric pulp test) showed no responses indicating necrosis of the pulp. The radiograph revealed an additional distolingual root (RE) with periapical radiolucency (Figure 7). The diagnosis of pulp necrosis was made and root canal treatment was planned.

The tooth was isolated with rubber dam. Access to the pulp chamber was made with endodontic access bur. Four canal orifices (mesio-buccal, mesio-lingual, disto-buccal and distolingual) were located using DG16 endodontic explorer. The pulp chamber was flushed with $2.5 \%$ sodium hypochlorite. The patency of the canals was checked with \#10 k files. The working length was confirmed using apex locator and working film radiograph, with four files in place (Figure 8). All four canals were cleaned and shaped using conventional hand $\mathrm{K}$ files with step back technique. Apical preparation was done till \# $30 \mathrm{~K}$ files in mesial roots and \# $35 \mathrm{~K}$ files in distal root. Irrigation was performed with $2.5 \%$ sodium hypochlorite and $17 \%$ EDTA solution during instrumentation. After completion of bio-mechanical preparation the canals were dried with sterile paper point and master cone radiograph was taken (Figure 9).Obturation was then performed with gutta percha and eugenol based sealer by lateral condensation technique. Post obturation radiograph was taken to verify the quality of obturation and access cavity was filled with temporary restoration (Figure 10). Patient was recalled for follow up and appropriate permanent restoration.
Figure 7: Pre-operative radiograph revealed three rooted mandibular first molar with an additional root located distolingually (RE)



Figure 8: Determination of working length of all four canals



Figure 9: Master cone radiograph

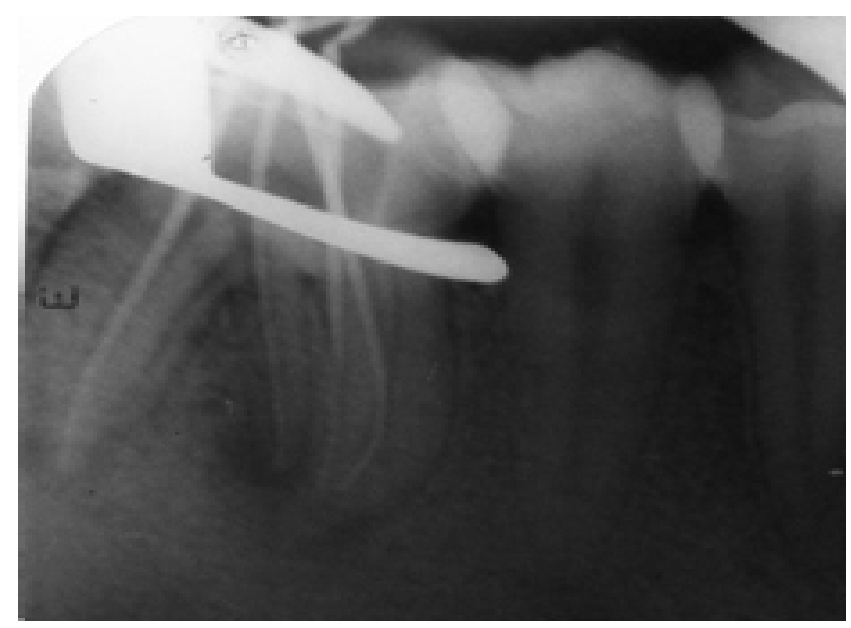


Figure 10: Post obturation radiograph

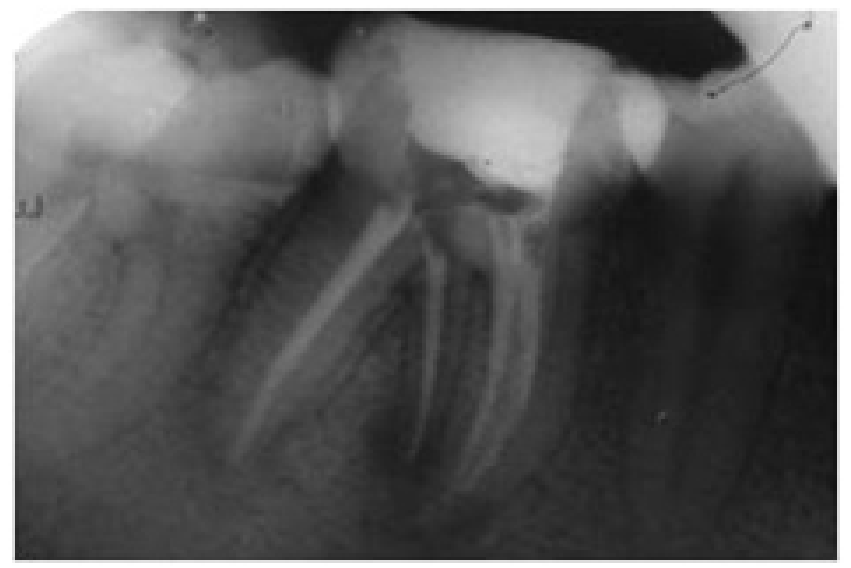

\section{DISCUSSION}

The present article reported three mandibular first molars: case one, with additional mesial root (radix paramolaris) and case two and case three, with additional distal root (radix entomolaris) and their subsequent endodontic management. Various literatures reported the occurrence of additional roots in both permanent and primary mandibular molars in different populations. However, there is paucity of literatures regarding the occurrence of extra roots in Nepalese population.

The majority of RE is found mostly in permanent mandibular first molar but it has also been found on second, and third mandibular molars, although it appears least frequently on second molars. The maximum frequency of RE in an African population is 3\% and in Eurasian and Indian population the frequency is less than $5 \% .{ }^{8}$ A frequency of $5 \%$ to more than $30 \%$ has been reported in the population with Mongoloid traits, such as the Chinese, Eskimos, and Native American populations. ${ }^{9-11}$ Bilateral occurance of radix entomolaris varies between 50 to $67 \% .^{12}$ Radix entomolaris is considered to be a normal morphological variant in mongoloid populations due its high occurrence. $9,13,14$

However, radix paramolaris is considered to be an extremly rare varient of mandibular molars. Visser in 1984 observed RP with the prevalence of $0 \%$ for the first mandibular molar, $0.5 \%$ for the second and 2\% for the third molar. ${ }^{15}$ However, there are studies available reporting the presence of RP in mandibular first molars. ${ }^{16,17}$ In African population the prevalence rate of RP is reported to be $1.5-3 \%$ but it is less frequent in Indian population with the existence rate of $2 \%{ }^{5}$

The morphology of RE and RP may vary from a short conical extension to a fully grown root with a normal length and root
canal.RE is located disto-lingually, usually appears smaller and more curved than disto-buccal root with its coronal part completely or partially fixed to the distal. ${ }^{8}$ In this case report the additional distolingual root in case number 2 appeared to be of normal length with normal root canal but in case number 3 the root appears smaller and more curved. RE is not only a division of distal root but it is a true additional root with separate root canal orifice and apex. ${ }^{18} \mathrm{RP}$ with an additional buccal root may be found as a separate or fused with the mesial root. ${ }^{8}$ In our case it was a separate root with normal root length and canal but more curved.

Carlsen and Alexandersen classified RE into four different types based on the location of its cervical part. Each type can be sub classified as separate and non-separateRE. ${ }^{16}$

Type A: RE with disto lingual location in which the root complex has two cone-shaped macrostructures.

Type B: RE with disto lingual location in which the root complex has one cone-shaped macrostructures.

Type C: RE with lingua location to the mesial root complex.

Type AC: RE with lingual location between the mesial and distal root complexes.

Present case reports the RE of type B and Type AC.

De Moor et al. classified RE on the basis of the curvature of the root or the root canal. ${ }^{5}$

Type 1: with a straight root or root canal.

Type 2: with a curved coronal third and straight middle and apical third

Type 3: with an initial curve in the coronal third and a second curve beginning in the middle or apical third with buccal orientation

Present case reports the RE of Type B and Type AC with straight additional roots and canals.

A superimposition of the roots can occur in a periapical radiograph; hence RE/RP remains undiagnosed. Ingle et al recommended that second radiograph should be taken at $20^{\circ}$ mesial angulations and one at $20^{\circ}$ distal angulations. These radiographic angulations aid to obtain basic information of tooth anatomy without much superimposition. ${ }^{19}$ Hence, all the radiographs in our cases were taken at $20^{\circ}$ mesial angulations 


\section{CONCLUSION}

An accurate diagnosis of external and internal morphological variation of tooth is extremely crucial to avoid complications and to decrease failure rate of root canal treatment. Failure to diagnose RE/RP may lead to missed canal and incomplete debridement of canal resulting in compromised treatment outcome. Hence, for successful endodontic therapy all the roots and canals should be located, cleaned, shaped and obturated. For the accurate diagnosis clinician should be aware of the existence of the morphological variation of the particular tooth and a second radiograph should be taken from a mesial or distal angulations.

\section{REFERENCES}

1. Vertucci FJ. Root canal anatomy of the human permanent teeth. Oral Surg Oral Med Oral Pathol; 1984;58(5):589-99. http:// dx.doi.org/10.1016/0030-4220(84)90085-9

2. Vertucci FJ, Williams RG. Root canal anatomy of the mandibular first molar. $J$ N J Dent Assoc 1974;45(3):27-8. PMid: 4523925

3. Carabelli G. Systematisches Handbuch der Zahnheilkunde;2nd ed. Vienna: Braumuller und Seidel, 1844:114.

4. Bolk L. Bemerkungen uber Wurzelvariationen am menschlichen unteren Molaren. Zeiting fur Morphologie und Anthropologie $1915 ; 17: 605-10$.

5. De Moor R, Deroose C, Calberson F. The radix entomolaris in mandibular first molars:an endodontic challenge. International Endodontic Journal 2004;37(11):789-99. http://dx.doi.org/ 10.1111 /j.1365-2591.2004.00870.xPMid:15479262

6. Carlsen $O$, Alexandersen V. Radix entomolaris: identification and morphology: Scan J Dent Res 1990; 98:363-73. PMid: 2293344

7. Carlsen $O$, Alexandersen V. Radix paramolaris in permanent mandibular molars: identification and morphology. Scan J Dent Res 1991;99:189-95. PMid:1871529

8. Nagaven NB, Umashankara KV. Radix entomolaris and paramolaris in children: a review of the literature: J Indian Soc Pedod Prev Dent 2012;30(2):94-102. http://dx.doi.org /10. 4103/0970-4388.99978 PMid:22918092

9. Curzon ME, Curzon JA. Three-rooted mandibular molars in the Keewatin Eskimo. J Can Dent Assoc (Tor) 1971; 37(2): 712.
10. Sperber GH, Moreau JL. Study of the number of roots and canals in Senegalese first permanent mandibular molars. Int Endod $J$ 1998;31(2):117-22. http://dx.doi.org/10.1046/j.1365-2591. 1998. 00126.x PMid:9868938

11. Turner CG. Three-rooted mandibular first permanent molars and the question of American Indian origins. Am J Phys Anthropol 1971 ; 34(2):229-41. http://dx.doi.org/10.1002/ajpa. 1330340207 PMid:5572604

12. Calberson FL, De Moor RJ, Deroose CA; The radix entomolaris and paramolaris:clinical approach in endodontics. Journal of Endodontics 2007; 33(1):58-63. http://dx.doi.org/10.1016/ j.joen. 2006.05.007 PMid:17185133

13. Ferraz JAB, Pécora JD. Three-rooted mandibular molars in patients of Mongolian, Caucasian and Negro origin. Braz Dent J1993; 3(2):113-7. PMid:8241760

14. Walker RT; Root form and canal anatomy of mandibular second molars in a southern Chinese population. J Endod 1988;14(7):325-9. http://dx.doi.org/10.1016/S0099-2399(88) 80192-4

15. Visser JB; Beitrag zur Kenntnis der menschlichen Zahnwur zelformen Hilversum: Rotting; 1948;49-72.

16. Carlsen O, Alexandersen V. Radix entomolaris: identification and morphology. Scan J Dent Res 1990; 98:363-73. PMid: 2293344

17. Sperber GH, Moreau JL. Study of the number of roots and canals in Senegalese first permanent mandibular molars. Int Endod $J$ 1998; 31:112-6. http://dx.doi.org/10.1046/j.1365-2591.1998. $00126 . x$

18. Tratman EK. Three-rooted lower molars in man and their racial distribution. Br Dent J 1938;64:264-74.

19. Ingle JI, Hei thersay GS, Hartwel GR. Endodontic diagnostic procedures. Ingle JI, Bakland LF, editors. Endodontics: 5 th ed. London: B.C. DeckerInc.; 2002. 203-58. 